\title{
General Editors' Preface to Collected Works of Bernard Lonergan
}

The project of publishing the Collected Works of Bernard Lonergan (CWL) was conceived while Lonergan was still alive, though he was no longer able to take any active role in its execution. The Trustees of his Estate, however, gave the project enthusiastic backing, designated the works to be included, appointed General Editors, and commissioned the Lonergan Research Institute as agent publisher. The Institute in turn engaged the services of the University of Toronto Press, which has continued to turn out handsomely printed volumes, as well as reprints of works published earlier that will be included only later in our cwL series.

The title of the series is Collected Works, not The Collected Works, by which we wish to indicate that it is not our purpose to include all the works of Lonergan in the familiar style of an Opera Omnia. Nevertheless, the collection will include the vast majority of his works, enough to permit a thorough study of all the main elements of his thought; and references to archival material will enable researchers to pursue their quest beyond these volumes for minutiae, fragments, sketches, memos, and so on not included here.

The order of the first dozen volumes as numbered (though not as appearing in print) will follow the main steps of Lonergan's public career in chronological order and so will start with his doctoral dissertation of 1940; later we will abandon chronology in order to go back and include works of his student days and of his early teaching years that throw significant light on the major works, as well as to collect scattered reviews, responses to questions, and other items of a less developed character, and to follow the development in his courses and institutes on method. 
Our editing policy is frankly conservative, taking it as our ideal to publish exactly what Lonergan said or wrote. The ideal, of course, is in many cases unattainable; for one simple example, we have sometimes had to reproduce what previous editors have given us, without knowing how much their editing changed the text; for another much more important example, we have often had to transcribe recordings of lectures that were never meant for publication and had to be rewritten (as Lonergan himself once requested) for the reading public. The mechanics of publishing a collection of over twenty volumes also required a good many minor changes, and so we have adopted a uniform spelling and punctuation, taking as our authorities for the most part the Oxford American Dictionary and The Chicago Manual of Style.

Still, the conservative principle has been dominant. There was no question, then, of changing language that would now be regarded as noninclusive, or of removing statements that are less ecumenical in tone than we would wish, or even of 'correcting' some of Lonergan's outdated language. This has a more important basis than mere fussiness; Lonergan had a lifelong concern for history, and the history of his own development is crucial to the interpretation of his ideas. Our decision, then, has been to leave intact whatever may help readers to locate a work in his history; if his earlier writing shows a preference for English usage and his later writing a preference for American, that is part of his history; if he spoke of 'gramophones,' that too points to his personal history.

For the rest we may conclude with all possible brevity. We have often added numbering and subtitles for his divisions (always recording that fact). We have translated in text or footnotes Lonergan's Latin and Greek quotations, words, and phrases, and have provided a lexicon for handy reference to them. We have checked his footnote references wherever possible, and have here and there provided editorial notes of our own.

As we go to press with this volume we are not quite halfway through the original project. We have incurred many debts of gratitude in these fifteen years and expect to incur many more as the work progresses. Since it is not possible to name all future collaborators and this Preface is meant to introduce the whole series, we have to be content at this point with a general 'Thank you' to those who have contributed and/or will contribute to our task: translating Lonergan's Latin, transcribing tapes, editing lectures, checking references, and performing the many office tasks associated with publishing. Here we may mention especially others who have accepted 
responsibility for editing certain volumes, and as well the staffs of the Lonergan Research Institute and of the University of Toronto Press.

Finally we acknowledge the financial help we have received from the sponsors of particular volumes; it was clear from the beginning that we would have to subsidize the series; we appealed for financial help, and it was given promptly, generously, and so joyfully that it seemed that we were the benefactors of those donating the subsidies rather than the reverse.

FREDERICK E. CROWE

ROBERT M. DORAN 
This page intentionally left blank 